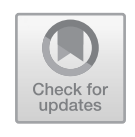

\title{
Building a Grounded Theory on Managing Standards in Innovation Contexts
}

\begin{abstract}
This chapter combines the patterns identified in the earlier chapters into a generalisable grounded theory and identifies the relationships between them. This grounded theory is based on a framework of three nested levels: (1) the company, which is part of (2) an industry, which is in turn part of (3) its wider context. The theory focuses on supporting factors and activities needed on the company- and industry levels to facilitate effective management of standards and regulation in innovation contexts. This chapter also shows how the three levels are linked together. The grounded theory explains how innovators can deal with demands and influences from the wider context by engaging in industry-level collaboration.
\end{abstract}

Keywords Innovation management $\cdot$ New product development Cross-company collaboration - Co-opetition - Managing standards and regulation - Managing societal needs

The empirical insights presented in the earlier chapters provide an excellent base for building theory on our research question and allows us to address the theoretical gaps outlined in Sect. 1.2.4. To do so, we develop a process model of the management. This model includes the activities needed to successfully introduce an innovative product to a regulated market where standards are needed, and a number of underlying structural elements that enable these activities.

(C) The Author(s) 2019

P. M. Wiegmann, Managing Innovation and Standards, https://doi.org/10.1007/978-3-030-01532-9_6 
As we already expected in Sect. 1.2, these activities occur at different levels. Figure 6.1 shows our general framework of the three nested relevant levels. In this framework, (1) a wider context encompasses (2) several industries, which in turn are made up of (3) a number of companies. Concerted activities on all three levels are necessary to align innovation and standards/regulation as achieved in the $\mathrm{mCHP}$ case (see Sect. 5.3).

Our further theorising fills in the blanks of Fig. 6.1 by looking closely at each level and identifying the factors which eventually lead to such an outcome. We build detailed theory about the company level (Sect. 6.1) and the industry level (Sect. 6.2). Finally, we consider how all of this relates to developments and the associated processes that occur in the wider context of an innovation (Sect. 6.3). Following these theory-building efforts, we end the chapter with some final thoughts on our findings (Sect. 6.4).

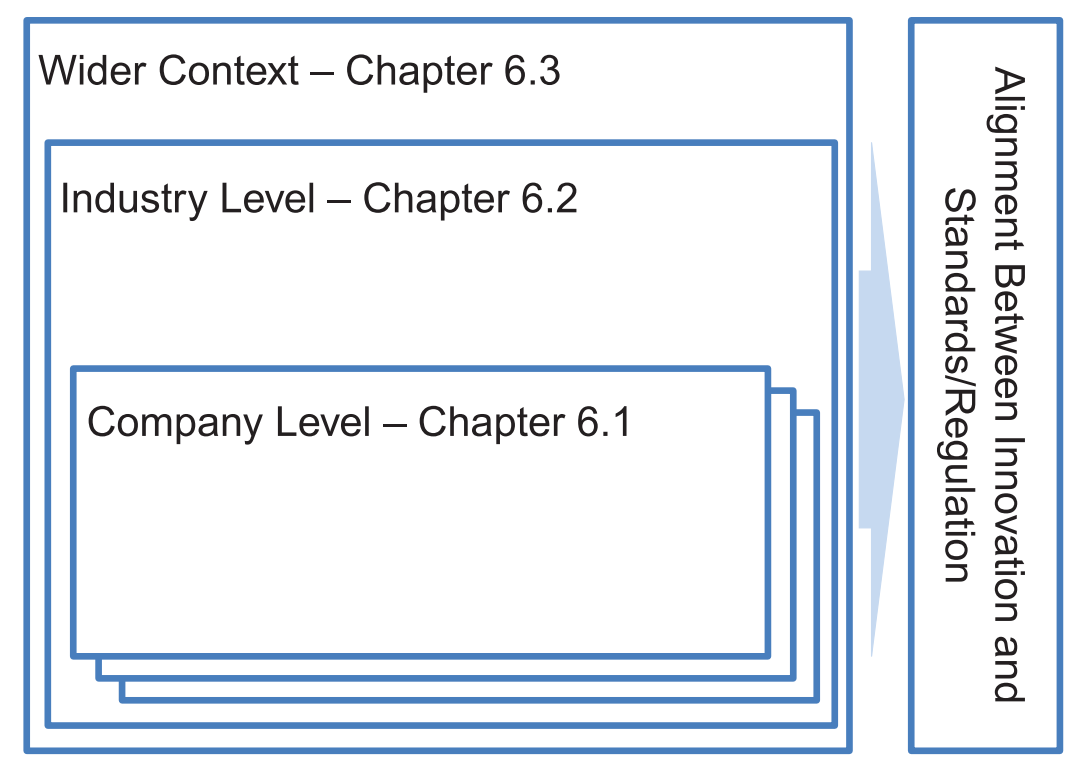

Fig. 6.1 Framework for a theory on managing standards in innovation contexts 


\subsection{Managing Standards and Regulation ON THE COMPANY LEVEL}

The different types of standards' - and by extension also regulation'sstrong implications for innovations make them key issues to manage in NPD contexts. We first consider the company level. In general, the observations from our case show that a number of supporting factors need to be in place as necessary conditions to form the foundation for managing standards and regulation successfully (shown in the bottom half of Fig. 6.2 and discussed in Sect. 6.1.1). Building on this, companies need to carry out several activities to ensure that an innovation fulfils all standard- and regulation-related requirements (shown in the top half of Fig. 6.2 and discussed in Sect. 6.1.2). These activities ultimately determine the degrees of freedom for the innovation, as we show in Sect. 6.1.3.

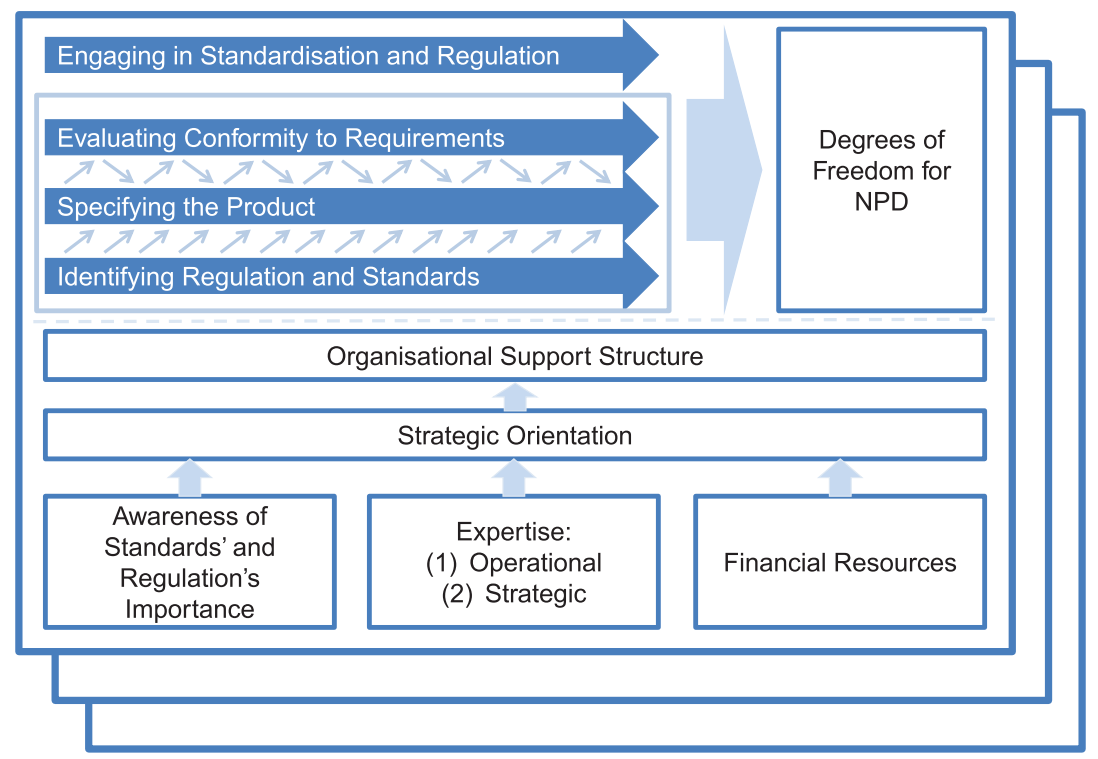

Fig. 6.2 Company-level management of standards and regulation in NPD contexts 


\subsubsection{Supporting Factors: Necessary Conditions for Managing Standards and Regulation}

We observed a number of recurring themes across the interviews (see the data presented in Sect. 4.1), which form the foundation for companies' activities. Having such a foundation in place appears to be a precondition for successfully addressing standards and regulation. On the most fundamental level, companies exhibit three key characteristics (awareness of standards' and regulation's importance, expertise, and availability of financial resources). These three key attributes drive the degree to which the company adopts a strategic orientation which in turn influences the organisational support structure for managing standards and regulation. We provide more detail about each of these aspects below.

\subsubsection{Key Characteristics: Awareness, Expertise, Financial Resources} Awareness of standards' and regulation's importance is the first key characteristic of companies that our data shows to be relevant. Our interviews demonstrate that companies differ substantially on this aspect (also see Sect. 4.1.1 and the characterisations of companies in Table 4.1). Some degree of awareness about this topic's importance is likely to emerge in any company by the time that the product enters conformity assessment. However, our case shows substantial variation in how aware companies actually are. Some firms' awareness was limited to the regulation-related aspects and only emerged once they addressed their product's certification. Companies at the other end of the scale showed deep knowledge of standards and regulation.

Expertise is a second key characteristic: Relevant knowledge can be grouped in two main categories: (1) operational, and (2) strategic. The operational expertise covers technical knowhow (which companies that are able to develop an innovation are likely to have) and topics related to effective participation in standardisation committees and industry collaborations (e.g. negotiating skills). We observe much more variance in companies' strategic expertise (e.g. abilities related to coordinating standardisation activities for different technologies in the company's portfolio, and contributing to the industry-level processes discussed in Sect. 6.2). This strategic expertise is needed for assessing the effects of standards and regulation and effectively managing the company's input in standardisation. 
While much of this expertise is company-internal, all interviewed companies also relied on external expertise in areas where their knowledge was insufficient (in our case mainly coming from consultants and notified bodies). This observation suggests that being aware of the limitations of one's own expertise and seeking outside help where needed is important for successfully managing standards and regulation for innovation. It also suggests that a company's ability to manage these topics relies to some extent on the industry structure, and in particular the supporting institutions (see Sect. 6.2.1), which can substantially facilitate the company's work. Providing support for the company is hence one key pathway through which the industry level impacts the company level.

Financial resources are the final key element underlying the management of standards and regulation that we identify in our data. Here, we see a contrast between established companies and the smaller start-ups whose limited financial resources constrain their ability to participate in standardisation and lobby for changes in regulation.

\subsubsection{Strategic Orientation and Organisational Support Structure}

The three key characteristics of companies identified above determine to what degree they are able to orient their standards- and regulationrelated work strategically. Our observations in Sect. 4.1.3 suggest that companies with little awareness, expertise, and financial resources tend to take a less strategic and more ad hoc approach. We therefore infer that these elements' presence is a necessary condition for a strong(er) strategic orientation. This manifests itself in aspects of the management, such as the degree to which standardisation activities are coordinated across the company and planned in advance.

This strategic orientation also forms the basis for an organisational support structure, which helps ensure that the innovation is systematically developed in line with requirements. An important function of this structure is assigning responsibilities both for operational management of standards and regulation, and for coordinating these activities across the company. In all interviewed companies, responsibility for operational tasks was tightly linked to the engineers developing a product. This appears to be good practice because of these tasks' technical nature and the close relationships between technical development work and standardisation/regulation efforts (see Sects. 4.2 and 6.1.2). 
In companies with a strong strategic orientation, the organisational support structures also encompass clearly defined responsibilities for tasks related to planning and coordinating standardisation/regulation-related work. ${ }^{1}$ In our case companies, these roles were attached to various organisational functions, including the new product development, regulatory affairs, and certification departments. Our data does not indicate that any of these affiliations is preferable per se, as long as the staff fulfilling this role are sufficiently influential within the company. Furthermore, companies can strengthen this organisational support by investing additional resources in full-time staff and tools supporting their work, such as the database tracking expertise related to specific standardisation/regulation topics that we observed at one company.

\subsubsection{Activities for Managing Standards and Regulation}

The factors discussed in Sect. 6.1.1 provide the basis for effectively managing standards and regulation in the innovation. The activities (depicted in the top half of Fig. 6.2) can be grouped into (1) core activities that are directly related to new product development (identifying regulation and standards, specifying the product, evaluating conformity to requirements) and (2) activities related to engaging at the industry level.

\subsubsection{Core Activities: Identifying Regulation and Standards, Specifying the Product, Evaluating Conformity to Requirements}

Based on the data outlined in Sects. 4.2.1, 4.2.2, and 4.2.3, we identify three core activities for managing standards and regulation which are part of the new product development process: (1) identifying applicable regulations and standards, (2) specifying the product, and (3) evaluating the product's conformity to the requirements. Carrying out all three in some form is necessary to ensure that the final product conforms to all applicable requirements. Nevertheless, we observe variation in how exactly firms pursue these tasks. This has implications for the degrees of freedom in new product development, as we outline below.

Before firms can take any action towards addressing standards and regulation in their NPD process, they need to know which requirements apply to their product, making identifying regulation and standards an

\footnotetext{
${ }^{1}$ Companies with an ad hoc approach tend to limit themselves to the operational tasks and therefore do often not address these duties in their support structures.
} 
essential task. Our observations suggest that companies should do so at a very early stage, possibly already when deciding whether to invest in a new technology. This enables them to shape their product in a way which meets the requirements from the outset. Firms need to continue identifying requirements throughout the NPD process because rules are subject to change, and because not all technological aspects where standards/regulation apply may be foreseeable at the outset of the NPD process.

We also observe that not all companies are able to do so on their own, due to lacking awareness and expertise. This may result in an ad hoc approach to the topic and missing organisational support. However, such firms can rely on supporting institutions from the industry (see Sect. 6.2.1) to 'outsource' this activity and rely on third parties (e.g. consultants, notified bodies, and-in the case of component suppliers-clients) to identify relevant requirements on their behalf. However, our case shows that doing so has two drawbacks for the subsequent activities: (1) In some situations, companies may have discretion over which standards and regulation that they apply to their innovation, e.g. when multiple directives could be applied. To take advantage of this opportunity, they need to be aware of potential alternatives and evaluate the alternatives' consequences. (2) Relying on an external party to stay informed about changing requirements may delay the point in time when companies learn about new developments. Consequently, all companies in our case that followed a strategic approach to managing standards and regulation emphasised the importance of identifying regulations and standards for the subsequent activities.

The requirements identified in this first step are fed into the process of specifying the product, which includes 'translating' the contents of standards and regulation into concrete requirements, and designing the product in such a way that it meets these requirements. The case shows that especially requirements related to safety often take a very high level of expertise to implement and consequently all interviewed companies relied to some degree on external expertise in this step, and also used standardised components which were proven beforehand to meet the requirements. This activity therefore, again, benefits from a well-developed industry structure with supporting institutions (see Sect. 6.2.1).

Finally, companies need to evaluate their product's conformity to the requirements as part of the NPD process. Our case shows that firms should ideally carry out a first evaluation when deciding whether to 
invest in a technology and then repeat the assessment at regular intervals throughout the process. An initial appraisal of the innovation's potential to conform to the requirements enables companies to estimate the needed effort to address the topic in the NPD process and-in the worst case-prevents them from investing in technologies that cannot be marketed due to barriers discussed in Sect. 3.5. A firm's ability to effectively conduct such an initial appraisal relies on its strategic orientation, because of the understanding needed to assess factors, such as the likely impact of standards and regulation and their potential future developments.

Once companies invest in developing a technology for which standards and regulation are relevant, the case suggests that they should regularly review its conformity, potentially with the help of industry-level supporting institutions if the company's own expertise is insufficient. Doing so throughout the process reduces the need for duplicating development work if the results are fed back into the product specification process in a timely manner.

\subsubsection{Engaging in Standardisation and Regulation}

Engaging in standardisation and regulation is an additional, optional outward-looking activity (see Sect. 4.2.2), which provides the main path for companies to influence their environment. The examples of the smaller start-up manufacturers in our case show that developing a product which is acceptable for the market is possible without directly influencing standards and regulation. However, doing so opens up additional opportunities because it allows companies to contribute to developments on the industry- and wider context levels and provides them with the additional option of attempting to adapt standards and regulation rather than the innovation when conforming to them is impossible or difficult (see Sect. 3.5).

These activities rely heavily on a strong foundation (see Sect. 6.1.1) because they are relatively resource- and knowledge-intensive (both in terms of money and expertise), and also require the company to adopt a strategic outlook on the technology. The hurdles for mCHP's market introduction would most likely have been too high (locking the technology out of the market) if none of the companies had taken the initiative to develop standards and influence regulation. Although this is clearly a benefit of this engagement, actors who did not contribute also benefit 
to a large extent from the results (see Sect. 5.3). This implies that companies need a high degree of strategic vision and long-term thinking, aiming to develop a 'large pie for everyone' rather than a 'small pie for themselves' (at the risk of 'having no pie at all'), to invest in influencing standards and regulation for a new technology. Such long-term thinking, both within the company and at industry level, is also needed to successfully navigate the dynamic processes related to this topic (see Chapter 5, Sects. 6.2 and 6.3).

\subsubsection{Degrees of Freedom for New Product Development}

The aspects outlined so far have strong implications for the degrees of freedom for developing a new product. Depending on how they are handled, companies may enjoy a large scope for developing their own solutions or may be somewhat more restricted in key areas.

The company in our case that perceived standards mainly as limiting its freedom in developing $\mathrm{mCHP}$ (see Sect. 4.2.4) is also the one that was the least invested in the activities outlined above and relied to a very large degree on notified bodies and consultants (also see Table 4.1). Even though the interviewee at this company commended the notified body for its flexible approach in conformity assessment, the company's relatively low level of activity made it more dependant on external parties. This may have contributed to reducing the room to implement its own solutions.

The data clearly shows the benefits of taking an active approach towards the tasks outlined above. By doing so, firms can create a substantial amount of 'space' for innovating. In particular, three factors explain how this 'space' can be created: (1) The leeway in identifying regulation and standards (see the discussion earlier in this chapter and Sect. 4.2.1), (2) the open nature of many standards and different ways of demonstrating conformity (see Chapter 3 ), and (3) the potential to influence standards and regulation (see the discussion above and Sect. 4.2.2 and Chapter 5). Companies in the case who managed the topic strategically combined these factors in various ways (see e.g. the example of bringing new methods for ensuring product safety into the standard in Sect. 4.2.4) in order to develop innovative solutions while ensuring the final product's fit to the requirements. Consequently, all interviewed actors who followed such an approach agreed that they enjoyed 
a relatively large degree of freedom for developing the innovation while benefitting from the relatively stable basis offered by standards and regulation described in Chapter 3.

\subsection{Industry Level Structure and Processes}

Following the theoretical analysis of the company-level management in the previous chapter, we now turn our attention to the industry level. Activities on the industry level are likely to focus on the standards which have the strongest impact on an innovation. In highly regulated markets, these standards are often linked to regulation (see Chapter 3 ).

Figure 6.3 summarises our findings regarding the work at the industry level. Again, we observe a number of underlying factors which contribute to an industry structure that facilitates activities in which standards and regulation are addressed (see bottom-half of Fig. 6.3 and Sect. 6.2.1). These activities are shown in the top of Fig. 6.3 and

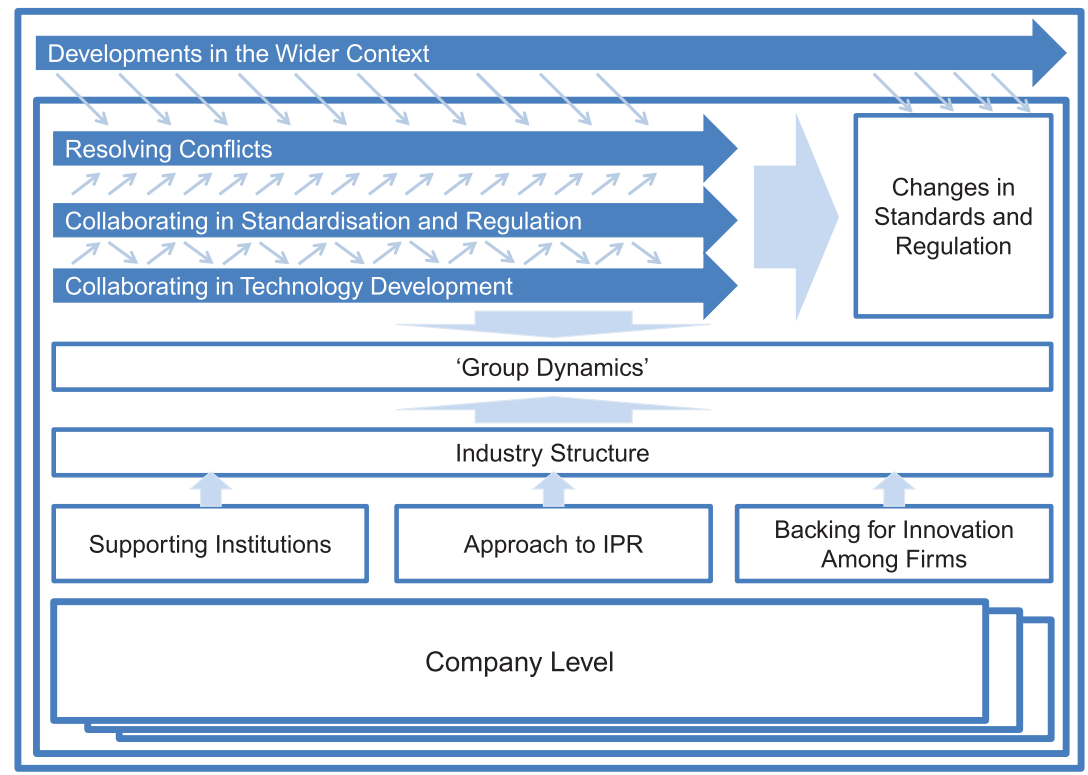

Fig. 6.3 Industry-level structure and processes for addressing standards and regulation 
discussed in detail in Sect. 6.2.2. Furthermore, developments in the wider context influence the industry-level activities and vice versa, as we show in Sect. 6.2.2 and discuss in more detail in Sect. 6.3.

\subsubsection{Key Elements of the Industry Structure}

Our case clearly shows that the industry-level activities happen on the background of certain industry structures that may support (as we observed) or hinder the process. While the industry structure obviously consists of many elements, most of which are beyond the scope of this study, the data presented in Sect. 5.1 reveal three fundamental elements: supporting institutions, approach to IPR, backing for the innovation among firms (shown at the bottom of Fig. 6.3). These elements explain much of the success that we observe in our case. Below, we elucidate them and show how they contribute to an industry structure that is conducive to addressing standards and regulation for an innovation. We also briefly consider how such an industry structure can emerge.

\subsubsection{Fundamental Elements: Supporting Institutions, Approach to IPR, Backing for Innovation}

First, throughout our data in Chapters 4 and 5 it becomes apparent how crucial a number of supporting institutions were for all aspects of the case. Their influence extends to company-internal management (as discussed in Sect. 6.1), industry-level collaboration, and attempts to influence standards and regulation. Table 6.1 summarises the supporting institutions which we encountered in the $\mathrm{mCHP}$ case and the functions that they fulfilled.

The list of institutions and functions in Table 6.1 is specific to our case and therefore unlikely to be exhaustive. For example, it is conceivable that NGOs could support an innovation with social and/or environmental benefits, and contribute to the management of standards and regulation by influencing policy makers and the public debate in the wider context (see Sect. 6.3) in that technology's favour. Although the composition and functions of supporting institutions are case-specific, presence of such institutions in general is likely to be important in managing the co-evolution of innovation, standards and regulation. Our case suggests that these supporting institutions' contribution to the process is even larger than the sum of the individual functions listed in Table 6.1. One reason for this is these institutions' lack of a direct (financial) 
Table 6.1 Overview over functions fulfilled by supporting institutions in the $\mathrm{mCHP}$ case

\begin{tabular}{|c|c|}
\hline Supporting institution & Functions \\
\hline External consultancy & $\begin{array}{l}\text { - Provide technical expertise and knowledge about applica- } \\
\text { ble regulation and standards } \\
\text { - Represent individual companies or the entire industry in } \\
\text { standardisation committees }\end{array}$ \\
\hline Notified bodies & $\begin{array}{l}\text { - Provide knowledge about applicable regulation and } \\
\text { standards } \\
\text { - Enable market access by issuing conformity certificates } \\
\text { - When harmonised standards are absent: translate 'essential } \\
\text { requirements' into concrete criteria }\end{array}$ \\
\hline Industry associations & $\begin{array}{l}\text { - Provide a forum for industry actors to agree on common } \\
\text { positions and 'talk with one voice' } \\
\text { - Provide access to regulatory processes for the industry } \\
\text { - Observe developments in adjacent areas of regulation and } \\
\text { standardisation }\end{array}$ \\
\hline Academic research institute & $\begin{array}{l}\text { - Support field trials and other collaborations for technol- } \\
\text { ogy development } \\
\text { - Provide independent technical expertise in standardisation } \\
\text { committees }\end{array}$ \\
\hline
\end{tabular}

interest in the technology's success, which lends the industry's claims and actions credibility. In addition to them facilitating much of the necessary work, both on the company- and industry level, they can therefore be seen as amplifying the impact of the innovators' own activities.

Second, we identify the approach to IPR as core to an industry structure which supports managing standards and regulation effectively. As we show in Sect. 5.1.4, actors in the case placed a high importance on IPR in technology development partnerships. However, they consciously decided to leave the topic out of activities directly related to standards and regulation. While the best way of handling IPR issues may be case-specific, our data shows that an industry needs to ensure that the chosen approach does not discourage others from joining the industry's efforts. Because collaborating in technology development and standardisation/regulation is key to the industry activities (see Sect. 6.2.2), the IPR regime must support them. This means that on the one hand all contributors' IP must be protected. On the other hand, no party should be able to use its IP for dominating the cooperation in a way that causes potential developers to refrain from or stop contributing to the 
technology. In addition, such domination by one party would likely also make the resulting standards unacceptable to other key stakeholders on whose support the innovation depends. Especially when these standards are linked to regulation (see Table 3.3), the approach to IPR must also be acceptable to regulators and other stakeholders. For example, standards which are used to specify essential requirements under the 'New Approach' should not incorporate IP that is subject to licensing. When addressing standards with no link to regulation, approaches to IPR that involve standard-essential patents (as commonly discussed in the literature, see Sects. 1.1 and 7.3.2) may be more acceptable.

The case suggests backing for the innovation among firms to be the third key element of the industry structure that determines to what extent the processes for addressing standards and regulation can be effective. Whether the majority key firms in the industry or only a few players support the innovation influences the extent of industry-internal conflicts, and how the innovation's legitimacy is perceived by outside actors. Furthermore, the degree of backing has ramifications for the 'group dynamics' that we discuss in Sect. 6.2.3.

\subsubsection{Emergence of the Industry Structure}

The three fundamental elements discussed above make up the parts of the industry structure that are relevant for the processes that we discuss in Sect. 6.2.2. When, as we observed in our case, these attributes are well aligned (i.e. a good network of supporting institutions is available, a fitting approach to IPR is employed, and there is widespread backing among firms) this structure provides a solid foundation for these processes. On the other hand, if some of the elements identified above are missing, this is likely to hinder the industry-level work needed to ensure alignment between the innovation and standards/regulation. In addition, such missing elements may have negative implications for company-level work.

Although our data does not offer detailed insights into how this industry structure has been built over time, it clearly is the result of a long-term development on which the companies were able to draw in the present case. Ultimately, this long-term development is likely to have been driven to a large extent by the individual companies in the industry who have been contributing to setting up supporting institutions, such as industry associations, and establishing an effective approach to IPR. Also the backing for the technology requires a long-term commitment, 
as our case shows. Individual companies can try enlisting their competitors in contributing to establishing these key fundamental elements, but are unlikely to succeed in building them on their own. Furthermore, some elements that can be leveraged in this context (e.g. NGOs as supporting institutions) may also appear without industry-actors' direct involvement.

\subsubsection{Industry-Level Processes for Facilitating the Innovation}

The elements of the industry structure outlined in Sect. 6.2.1 underlie the joint industry-level activities that eventually lead to changes in standards and regulation needed to support an innovation. In our case, we categorise industry-level activities (see Chapter 5) into three core processes: (1) collaborating in technology development, (2) collaborating in standardisation and regulation, and (3) resolving conflicts. As the case and our further discussion below show, it is essential for achieving the needed changes in standards and regulation that these processes are jointly driven by companies from the industry (unless one innovator is strong enough to 'push them through' alone), and that need to be coordinated well in order to deliver the desired results.

The findings from Sect. 5.1 suggest that collaborating in technology development both helps actors in the industry to jointly overcome technological challenges in some areas and also provides a basis for the further activities. Through their joint engagement in developing an innovation, actors in an industry (1) share a strong interest in the technology's success, (2) develop a common outlook on standardisation and regulation issues, and (3) can more easily address technological issues, that arise in the process of developing standards/regulation, together. These points also contribute to a tight link between technology development and collaborating in standardisation/regulation. For example, evidence created in technology development cooperation projects was directly used in discussions on standards with other stakeholders in the mCHP development process (see Sect. 5.2.1).

Both types of collaboration benefit from a well-developed industry structure (see Sect. 6.2.1). Supporting institutions facilitate the cooperation because they provide already established forums where the work can take place, help coordinate the activities, and provide expertise and access to policy makers. An appropriate approach to IPR ensures that participating in cooperation is viable in terms of protecting one's own 
input while avoiding that certain actors can dominate the technology's development through their patents. Nevertheless, even when these factors are present, some conflicts may occur. Conflicts are particularly likely if important actors in the industry do not back the innovation (as could be observed in our case, see Sect. 5.1.3). Furthermore, the developments in the wider context about which we theorise in Sect. 6.3 may also contribute to conflicts, as could be observed in our case. This makes resolving conflicts a final key activity on the industry level to ensure that the changes in standards and regulation needed for an innovation can be achieved. Also for this key activity, our data shows the industry structure's importance for this issue, with supporting institutions playing key roles in helping to solve these issues (see Table 6.1).

\subsubsection{Individual Companies' Contribution to Industry-Level Processes}

The industry-level processes are chiefly driven by individual companies' contributions. Although the case shows that these processes often last several years and companies need a strategic long-term view to navigate them effectively, their results are much more immediate than building the industry structure outlined earlier. Furthermore, the industry-level processes enable companies to collaborate on those activities that are needed to align the technology, standards, and regulation, which cannot be carried out at company-level. Especially for companies which have insufficient clout on their own for driving changes in standards/regulation and engaging with the wider context (see Sect. 6.3), contributing to these processes is the key path to influencing developments at the industry- and wider context levels.

\subsection{3 'Group Dynamics' in the Industry}

As we observed in Sect. 5.1.3, the industry structure and collaboration processes in the $\mathrm{mCHP}$ resulted in certain 'group dynamics'. In our case, the strong support among industry and the obstacles to implementing the innovation, which were perceived in common across most involved actors, created mCHP's backers forming a very closely-knit group. They adopted a strong 'us vs. them' mentality when dealing with any parties not supporting the innovation. On the other hand, a lack of support and conflicting perceptions of the technology's environment may result in very contentious 'group dynamics'. 
Our case shows that such 'group dynamics' cause the involved companies to adapt a common outlook on the technology and what was needed to make it successful. Consequently, in such a setting, few disagreements between firms are likely to occur and the processes for resolving conflicts are mainly needed in dealing with the wider context instead of addressing industry-level issues. This common outlook and 'us vs. them' mentality also enables an industry to speak with one voice when addressing topics in the wider context.

However, on the other hand such a closely-knit group of actors also may have drawbacks. First, it may endanger the industry of entering a 'groupthink' mode of acting. More importantly, it may impact on how the industry is seen by stakeholders in the wider context. 'Group dynamics', such as the ones observed in the $\mathrm{mCHP}$ case, carry the risk that the industry is perceived as a colluding group, which writes its own rules and engages in regulatory capture. Our data does not show whether mCHP's backers were indeed perceived in this manner, but the discussion on how to interpret the industry's own energy efficiency calculation method in the wake of the Volkswagen Diesel scandal (see Sect. 5.2.2) shows that some actors were aware of this risk. Potentially, the credibility given to the technology by some of the supporting institutions (see Sect. 6.2.1) may also counter-act this threat, although more research is needed to investigate this.

Despite these possible pitfalls of acting as a too closely-knit group on the industry level, our case suggests that doing so generally supports the industry-level processes. The benefits of reduced conflicts and 'speaking with one voice' are potentially substantial and supported mCHP's development considerably. The collaborations to develop the technology and in particular the successful handling of the European Commission's intervention in the energy-labelling issue would have been hampered by other possible constellations of actors. Similar benefits are also likely to apply to other cases.

\subsection{Developments and Associated Processes IN THE WIDER CONTEXT}

As a final area within the three levels of our framework (see Fig. 6.1), our case shows the importance of developments in the innovation's wider context beyond the industry, and the associated processes of managing them. 
All our interviewees repeatedly stressed the importance of managing links with interests and actors outside the industry, such as regulators and developers of other technologies. Furthermore, our data reveals the aspects of standardisation related to the wider context to be both the most contentious topics in the $\mathrm{mCHP}$ case, and the ones demanding the most attention of the innovators (see the introduction to Sect. 5.2).

In the $\mathrm{mCHP}$ case, we observed three such important developments, which also were intertwined at some points: (1) One related to changes in access to the electricity grid, (2) trajectories of other innovations that were emerging simultaneously in that space (e.g. renewable energy generation, see Sect. 5.2.1), and (3) events related to political agendas and policy objectives that drove regulators' activities (e.g. reducing $\mathrm{CO}_{2}$ emissions and promoting renewable energy, see Sect. 5.2.2). In addition, several interviewees expected trends relating to re-use, recyclability and reparability (RRR) to become similarly impactful in the future. Beyond these examples, other types of developments could play similar roles in other cases. For example, both important societal debates, ${ }^{2}$ and scientific findings on risks associated with an innovation ${ }^{3}$ could have substantial implications for a technology's standards and regulation. Overall, these types of trajectories in the wider context are therefore highly relevant elements for theorising as part of the three levels in our framework.

Our case offers a clear picture of how these developments interact with the activities on which we focus in this study. While the case does not provide detailed insights into these trajectories themselves, it does thus offer an excellent basis for theorising about their interactions with standards in an innovation's development. Figure 6.4 shows these interactions and provides a more detailed look at the link between the industry level and the wider context shown in the topmost part of Fig. 6.3.

In Sect. 6.3.1, we discuss the relevance of these developments further and shed light on their effects on an innovation's development. We then theorise in Sect. 6.3.2 about strategies that actors in an industry can use to influence developments in the wider context.

\footnotetext{
${ }^{2}$ The societal debate following the revelations regarding the automotive industry's emission-testing practices can be seen as an example of this.

${ }^{3}$ For example, scientific findings about certain medical treatments' effectiveness may have implications for standards and regulation concerning innovations in drugs for these treatments.
} 


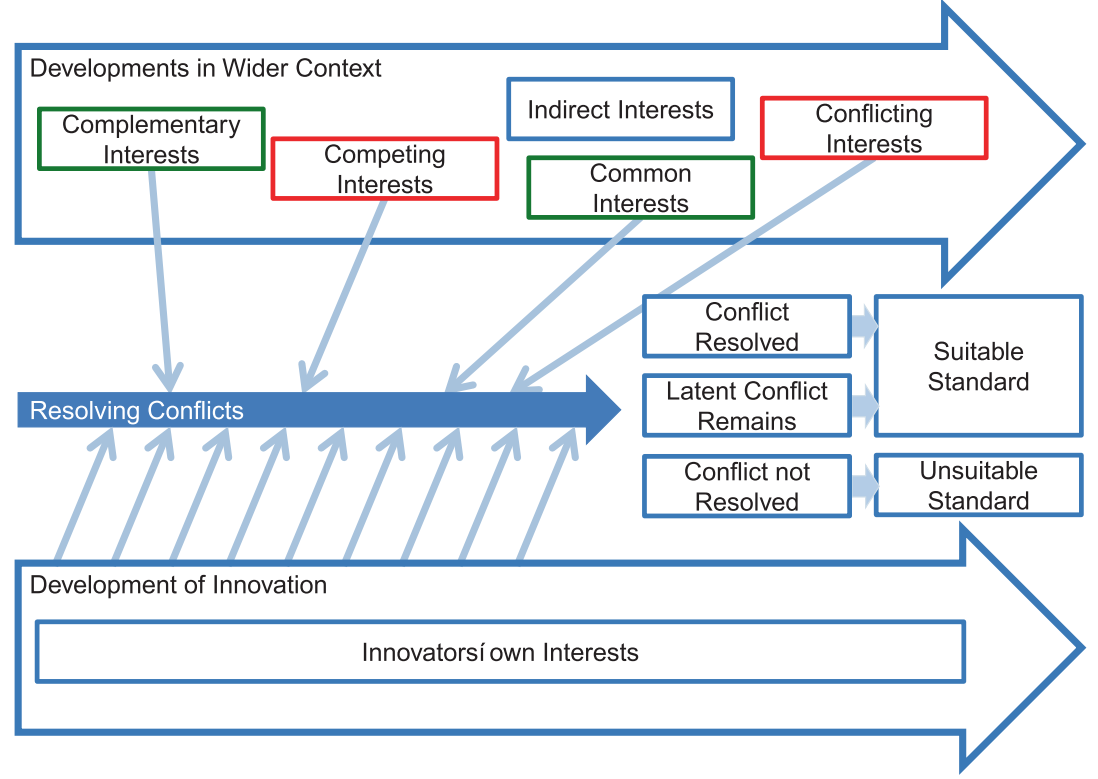

Fig. 6.4 Interactions between the innovation and developments in the wider context

\subsubsection{Relevance and Effects of Developments in the Wider Context}

The types of trajectories outlined above are driven by interests, which in many cases may not be aligned with the needs of a specific innovation, and can directly lead to new requirements. For example, the data presented in Sect. 5.2.1 shows how designers of renewable energy generation technologies and grid operators drove changes to grid connection standards with which $\mathrm{mCHP}$ had to comply. In terms of standards that innovators may encounter (see Sect. 3.5), such processes in the wider context are by definition always relevant for standards that relate to regulation (which is made by policy makers and other actors who are part of the wider context). However, work in areas with no link to regulation may equally be impacted by the wider context, for example when standards define interfaces to a larger system, such as the electricity grid in the $\mathrm{mCHP}$ case. 
Table 6.2 Examples of different types of interest in interactions with the developments related to electricity grid access in the $\mathrm{mCHP}$ case

\begin{tabular}{|c|c|c|}
\hline Type of interest & Example of Interest & Actor(s) holding the interest \\
\hline Innovators' own interest & $\begin{array}{l}\text { Secure access to electricity grid } \\
\text { for } \mathrm{mCHP} \text { appliances }\end{array}$ & Developers of $\mathrm{mCHP}$ \\
\hline Common interest & $\begin{array}{l}\text { Gain access to electricity grid } \\
\text { for small generators }\end{array}$ & $\begin{array}{l}\text { Producers of renewable power } \\
\text { generators }\end{array}$ \\
\hline Complementary interest & $\begin{array}{l}\text { Shift balance of electricity } \\
\text { generation away from large } \\
\text { competitors }\end{array}$ & Small electricity providers \\
\hline Competing interest & $\begin{array}{l}\text { Allow wider frequency bands in } \\
\text { electricity grid }\end{array}$ & $\begin{array}{l}\text { Producers of renewable power } \\
\text { generators }\end{array}$ \\
\hline Conflicting interest & $\begin{array}{l}\text { Retain easily manageable grid } \\
\text { by keeping small generators } \\
\text { out }\end{array}$ & Grid operators \\
\hline Indirect interest & Exit nuclear power & German government \\
\hline
\end{tabular}

Such external influences can be positive or negative for the innovation, and may therefore ultimately lead to conflicts. This depends on the interests that are at stake. In our case, we identify six relevant types of interest (see Table 6.2 for one example of each from the interactions concerning mCHP's grid-access ${ }^{4}$ ). (1) Innovators have their own interests in how the wider context should develop. (2) These interests may be shared with other actors who have a common interest. (3) Actors may also have complementary interests, which can be supported by developments that are in line with the innovators' own interest. On the other hand, there may be (4) competing interests which aim to achieve an outcome that is incompatible with the innovators' needs. Finally, there may be (5) conflicting interests that collide head-on with the innovators' goals. In addition, there may be (6) indirect interests, which are only indirectly linked to achieving outcomes in the wider context that support the innovation.

As the examples in Table 6.2 show, the interests and associated actors that are involved in the industry's wider context are likely to be highly diverse, making the developments that take place there very dynamic. Depending on how these interests are distributed among the actors in the wider context, these developments may be contentious issues. This

\footnotetext{
${ }^{4}$ Details can be found in Sect. 5.2.1
} 
requires an innovation's supporters to adopt a careful approach, as we outline in the following chapter.

\subsubsection{Influencing Developments in the Wider Context}

The kinds of development outlined in above are often embedded in major movements, such as the efforts to reduce $\mathrm{CO}_{2}$ emissions. They may involve many stakeholders with diverse interests from different industries, governments, NGOs, consumers, and other actors. Also the logics of change in different wider context s vary and may not always be completely transparent, as the interaction with the European Commission in our case shows (see Sect. 5.2.2).

Consequently, innovators tend to hold relatively little sway over external developments, although the exact extent to which they can influence them is case-specific. For example, the developers of mCHP had a much smaller influence in developing standards for access to the electricity grid than when handling the requirements for energy labelling (see the data in Sect. 5.2). Within the bounds of this influence, innovators can take an active approach to managing these developments as part of the process of resolving conflicts (see Figs. 6.3 and 6.4). Our case exhibits four basic strategies that can be used as part of such an active approach, which we summarise in Table 6.3.

These four strategies are not mutually exclusive. They can be used in parallel, even for influencing one development in the wider context, as the interactions with the developments regarding grid-access standards in our case show. This reflects the multitude of interests and associated actors involved that we outlined in Sect. 6.3.1. Each of the four strategies has certain prerequisites, which to a large extent relate to interests of other actors and the structure of the wider context (see Table 6.3). Actors with common or complementary interests can therefore be involved in coalitions, whereas competing and conflicting interests may be addressed by lobbying (if the associated actors are open to discussions) and/or adapting the technology accordingly. Furthermore, actors with competing and conflicting interests may sometimes also not be able to act on these interests. In these cases, persisting with own preferences may be an appropriate course of action.

\footnotetext{
${ }^{5}$ Again, this list may not be complete and other potential strategies, which we did not observe in our case, may exist.
} 


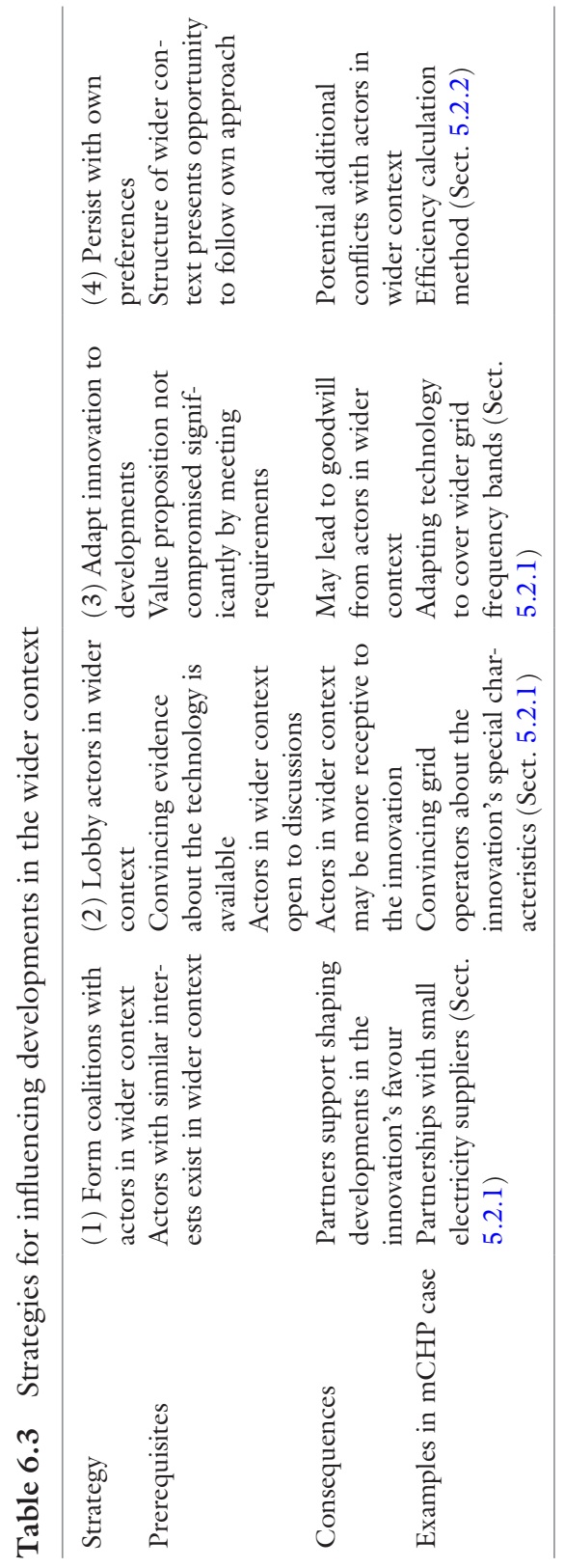


Through the consequences named in Table 6.3, the four strategies contribute to the outcome of innovators' attempts to resolve conflicts. Three such results are possible: (1) In the best case, conflicts with actors in the wider context are resolved, leading to the development of standards that are suitable for the innovation (i.e. standards with which the innovation can conform, see Sect. 3.5). In our case, we observed this outcome in many technical areas which were key for grid-access where small generators could eventually be connected to the electricity grid (see Sect. 5.2.1). (2) In addition, suitable standards can be developed following innovators persisting with their preferences. In this situation, which we observed in our case on the efficiency calculation issue (see Sect. 5.2.2), latent conflicts with other actors in the wider context may remain. Even though this outcome initially supports the innovation's market introduction, any latent conflicts may re-emerge later on and potentially lead to new problems. For example, in resolving the questions related to the calculation method in our case it was initially unclear how market surveillance authorities would treat the industry's use of its own standards instead of the European Commission's method and whether this would lead to further issues. (3) Finally, industry actors may also fail to resolve conflicts to their satisfaction and face resulting standards with which the innovation cannot easily conform. As we observe on the issue of grid frequency (see Sect. 5.2.1), this is a likely outcome for issues where there are insufficient actors in the wider context with whom alliances can be formed and competing/conflicting interests are too strong.

In conclusion, developments in the innovation's wider context are driven by a large variety of actors with diverse interests that may favour an innovation or oppose it. Depending on how these interests are eventually balanced, this context can boost an innovation or pose substantial barriers. Innovators tend to have limited influence on the wider context, which also depends on factors like the interests at stake, and the logic according to which changes in a development happen. While avenues for actively influencing these developments are available, their success ultimately depends on the characteristics of the specific development.

\subsection{Final Thoughts on Our Grounded Theory}

In the introduction to this chapter and Fig. 6.1, we claimed that innovators' activities on the company-, industry-, and wider-context levels need to be concerted in order to achieve alignment between an innovation 
and the applicable standards/regulation. Our discussion shows this to be true. While an innovation is ultimately driven by individual companies that develop the technology, any needed changes in standards and regulation require action on the other levels. We already expected the link between the company- and industry levels but also discovered the significance of the wider context.

As our theory shows, these links mean that the processes which we study are not linear but highly dynamic. They depend on the input of a large variety of actors, in addition to the companies developing the innovation. These actors may have very different stakes in the innovation and diverse functions to fulfil. These functions include, for example, industry associations providing forums for collaboration and supporting lobbying efforts, governments offering stability for the innovation, or consultants and researchers supplying expertise in key areas. Furthermore, not all actors involved in the process may be in favour of the innovation. This poses some of the most significant challenges for aligning the innovation, standards, and regulation.

Beyond this, our findings also mean that aligning the innovation with standards and regulation is not a goal in itself. The mCHP case shows that doing so may often be a necessary condition for introducing a technology into the market. Additionally, the observations in Sect. 6.3 suggest that the function of standards and regulation goes much further. Arguably, standards and regulation fulfil a key function of translating the large trends and needs in a technology's wider context (e.g. reducing $\mathrm{CO}_{2}$ emissions, building a stable electricity grid) into concrete technical requirements for a product. This means that aligning an innovation with standards equally contributes to aligning the innovation with the demands of key actors in the wider context on whom it ultimately depends for its success. The theory, which we have built based on the evidence from the $\mathrm{mCHP}$ case, offers guidance on how this can be achieved. This makes our theory a theory at the core of developing an innovation, going beyond the theory about managing standards that we anticipated building when we initiated this study. 
Open Access This chapter is licensed under the terms of the Creative Commons Attribution 4.0 International License (http://creativecommons.org/licenses/ by $/ 4.0 /$ ), which permits use, sharing, adaptation, distribution and reproduction in any medium or format, as long as you give appropriate credit to the original author(s) and the source, provide a link to the Creative Commons license and indicate if changes were made.

The images or other third party material in this chapter are included in the chapter's Creative Commons license, unless indicated otherwise in a credit line to the material. If material is not included in the chapter's Creative Commons license and your intended use is not permitted by statutory regulation or exceeds the permitted use, you will need to obtain permission directly from the copyright holder.

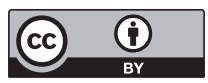

